Running head: COMMENTS AND CREDIBILITY

\title{
Comments and Credibility: How Critical User Comments Decrease Perceived News Article Credibility
}

Teresa K. Naab, Dominique Heinbach, Marc Ziegele \& Marie-Therese Grasberger

The published version of this manuscript is available here:

Naab, T. K., Heinbach, D., Ziegele, M. \& Grasberger, M.-T. (202020). Comments and

Credibility: How Critical User Comments Decrease Perceived News Article Credibility.

Journalism Studies. Advance online publication.

https://doi.org/10.1080/1461670X.2020.1724181

Dr. Teresa K. Naab, Department of Media, Knowledge and Communication, University of Augsburg, Universitaetsstrasse 10, 86159 Augsburg, Germany. E-Mail: teresa.naab@phil.uni-augsburg.de,phone: +498215985933, https://orcid.org/0000-00017345-2559, Twitter: @NaabTeresa.

Dominique Heinbach, M.A., Heinrich-Heine-University Duesseldorf, Universitaetsstrasse 1, 40225 Duesseldorf. E-Mail: heinbach@ phil.hhu.de, phone: +492118111593, Twitter: @ HeinbachD.

Jun.-Prof. Dr. Marc Ziegele, Heinrich-Heine-University Duesseldorf, Universitaetsstrasse 1, 40225 Duesseldorf. E-Mail: marc.ziegele@hhu.de, phone: +492118111568, https://orcid.org/0000-0002-2710-0955, Twitter: @ziegelem.

Marie-Theres Grasberger, M.A., Department of Media, Knowledge and Communication, University of Augsburg, Universitaetsstrasse 10, 86159 Augsburg, Germany. 
Correspondence concerning this article should be addressed to Dr. Teresa K. Naab, Department of Media, Knowledge and Communication, University of Augsburg, Universitaetsstrasse 10, 86159 Augsburg, Germany. E-Mail: teresa.naab@ phil.uniaugsburg.de, phone: +498215985933 , https://orcid.org/0000-0001-7345-2559, Twitter: @NaabTeresa.

\section{Funding}

Study 1 of this research was supported by the Digital Society research program funded by the Ministry of Culture and Science of the German State of North RhineWestphalia.

\section{Disclosure Statement}

The authors have no potential conflict of interests regarding this manuscript.

\section{Data Availability Statement}

The data supporting the analyses in this manuscript are available from the authors upon request. 


\title{
Comments and Credibility: How Critical User Comments Decrease Perceived News Article Credibility
}

\begin{abstract}
Many online user comments criticize the quality of news coverage. We conducted two experimental studies to assess the effects of such critical comments on readers' perception of the credibility of news articles and to analyze the effectiveness of counter-measures. Findings suggest that critical user comments can reduce readers' perceived credibility of a news article. We also demonstrate that this effect depends on whether a critical user comment receives Likes or not. Additionally, readers' credibility perceptions can be restored when a critical comment receives a reply comment by a user that includes counter-speech. A disagreeing reply by a moderator is less effective. The findings provide important implications for research on credibility perceptions in online environments and for the effects of user-generated counter-speech and interactive moderation.
\end{abstract}

Keywords: user comments, credibility, interactive moderation, media criticism, online news, experiment, counter-speech 


\section{Comments and Credibility: How Critical User Comments Decrease Perceived News Article Credibility}

In the contemporary media environment, news articles are often accompanied by usergenerated information. On the websites of various news outlets and on the Facebook, Twitter, or Instagram pages of these outlets, users can comment on many articles and use the Like and other reaction buttons to express an opinion. These forms of social information (Metzger, Flanagin, \& Medders, 2010; Peter, Rossmann, \& Keyling, 2014) indicate, more or less precisely and well-directed, how readers of news stories think about topics, actors, or the journalistic product. That way, they offer alternative perspectives and additional information to issues raised by journalists (Wendelin, Engelmann, \& Neubarth, 2015) and provide citizens with the opportunity to engage in interactive discussions with others (Diakopoulos \& Naamann, 2011; Springer, Engelmann, \& Pfaffinger, 2015). These possibilities of public user-generated content have sparked hopes for democratizing effects in that citizens would participate in the public discourse, while news outlets would provide a forum for these discussions and disseminate the various opinions to a large audience (Ruiz, Domingo, Micó, Díaz-Noci, Meso, \& Masip, 2011). Traditionally, news outlets have engaged in this role through - among others - letters to the editor, which offered a place for various opinions, shared conversation, and criticism. User comments can be considered a successor to this traditional form of reader feedback. Yet, they also introduced some unique features, such as the opportunity of anonymous participation and inclusive discussions, faster and interactive exchange between readers, and a diversified and much larger group of participants (McCluskey \& Hmielowski, 2011). From an economic point of view, the image of news outlets might benefit from allowing readers to discuss in comment sections in an appropriate manner and thereby contribute to the news interpretation process (Vujnovic, 2011; Ziegele \& 
Quiring, 2013). Some journalists appreciate user comments (MacGregor, 2014) and, for example, accept them as a valuable source of information (Duffy, Ling, \& Tandoc Jr, 2017). Others primarily feel negative about comments (Bergström \& Wadbring, 2015; Viscovi \& Gustafsson, 2013). A particular cause of these negative attitudes, according to various studies, is the proliferation of uncivil, abusive, or overly critical comments (Craft, Vos, \& Wolfgang, 2016; Loke, 2012; Robinson, 2010; Reich, 2011). Wright and colleagues, too, suggest that journalists assume a general potential of comments for public discourse, yet they also experience relevant challenges including severe criticism of their work (Wright, Jackson, \& Graham, 2019)

In fact, content analyses have shown that user comments on the websites and Facebook pages of news media outlets are predominantly adverse and critical towards the news articles or the issues reported (Coe, Kenski, \& Rains, 2014; Prochazka \& Schweiger, 2016). Such comments, according to previous research, can negatively affect readers' evaluation of the quality of the respective news articles, although the evidence regarding which quality dimensions are actually influenced by these comments is inconsistent (Dohle, 2018; Kümpel \& Springer, 2016; Prochazka, Weber, \& Schweiger, 2018). The current studies investigate the effects of critical user comments on perceived article credibility. Thereby, the studies focus on a quality dimension that has been considered as crucial in the context of a potential trust crisis of the news media (Fletcher \& Park, 2017), but that is yet to be comprehensively examined in empirical studies.

Additionally, few studies have investigated how feedback to critical comments in online discussions affects the influence of these critical comments. The current studies aim at filling this gap by examining how direct and indirect social information (Peter et al., 2014), such as Likes to a comment and reply comments written by users and professional community moderators, change the effects of critical comments on readers' credibility 
judgments. The findings contribute to a better understanding of the relevance of media criticism in user-generated content and provide an empirical estimate of the effectiveness of potential counter-measures.

\section{Recipients' Perceptions of News Credibility}

Credibility is a central parameter in people's perception and evaluation of news content (Kohring \& Matthes, 2007). Marchionni (2015) defines credibility as "a multidimensional construct that measures the perceived believability of a message (article), source (journalist or news site) or medium” (p. 235). Some communication scholars prefer the term "trust" over "credibility", but, essentially, draw on similar concepts (Kohring \& Matthes, 2007). Credibility perceptions of journalistic content are often measured with items referring to perceived believability, trustworthiness, and authenticity. Criteria such as perceived accuracy and impartiality are used in credibility research, too (Appelman \& Sundar, 2016; Flanagin \& Metzger, 2000). Generally, according to the definition by Marchionni (2015), credibility is not inherent in a communicator or message, but is always constructed by recipients ("perceived believability"). In contrast to that, news quality can be measured along normative and predefined criteria (e.g., by analyzing particular characteristics of the content of a message, Urban \& Schweiger, 2014) as well as it can be measured subjectively (e.g., by asking people about their quality perceptions, Prochazka et al., 2018). Scholars then refer to similar criteria used to describe perceived credibility, for example, perceived accuracy and impartiality (Urban \& Schweiger, 2014).

Although recipients rate criteria of journalistic quality, like balance, relevance and impartiality, as important (Tsfati, Meyers, \& Peri, 2006), experimental research suggests that the occurrence of these criteria in journalistic products hardly affects the recipients' evaluations of journalistic content (Urban \& Schweiger, 2014). Instead, users appear to rely on information that is less complex and easier to evaluate (e.g., Fichter \& Jonas, 2008). This 
phenomenon is often explained with theories of dual processing (e.g., Petty \& Cacioppo, 1986). Especially when consuming news online, recipients do not necessarily read articles carefully, but rather scan through them (Weinreich, Obendorf, Herder, \& Mayer, 2008). Therefore, judgments about the content are likely to be based on peripheral information rather than on the actual quality of the journalistic content (Prochazka et al., 2018). Moreover, online recipients are confronted with a multitude of information. In consequence, they tend to consider peripheral information when assessing the credibility of an object. Especially social information provided by other users, such as Likes and comments, helps users to evaluate the credibility or quality of journalistic content (Metzger et al., 2010).

\section{Social Information and Perceived Credibility}

In social media, journalistic content is often accompanied by various forms of "online social information" (Metzger et al., 2010; Peter et al., 2014). Indirect social information includes aggregated user evaluation ratings, such as Likes and reactions. Scholars investigating social information have used various labels like popularity cues or approval ratings (Haim, Kümpel, \& Brosius, 2018). Evaluation buttons such as the "Like" button are low-effort means to express one's judgment about journalistic content (e.g., Likes to an article) or content generated by other users (e.g., Likes to a comment). Independent of the intended meaning of a particular Like (Crawford \& Gillespie, 2016), the aggregated ratings indicate a summary statement of general approval or disapproval and they can affect readers in a similar way as statistical summary information in traditional news coverage (Lee \& Jang, 2010). Direct social information includes explicit recommendations by users or user comments on professional or user-generated content. In contrast to aggregated indirect social information, direct social information provides individual, vivid, and accessible information and therefore resembles the so-called exemplars of traditional news coverage (Zillmann, 2002). 
Recent research has supported the assumption that social information, such as Likes and comments, affect users' perceptions, attitudes, and behaviors (e.g., Haim et al., 2018). Among the results are effects of social information on readers' selection of and exposure to online news content (e.g., Messing \& Westwood, 2014), effects on readers' attitudes towards the issues reported (e.g., Heinbach, Ziegele, \& Quiring, 2018; Jin, Phua, \& Lee, 2015), and effects on readers' judgements of the journalistic product (see below). A theoretical approach to explain the effects of social information is rooted in dual processing: When individuals process information on a peripheral route, they may use social information as heuristic cues to evaluate the credibility of this information (Dohle, 2018; Prochazka et al., 2018). Other authors have suggested that indirect social information (i.e., Likes and Shares) could serve as anchoring heuristics (Porten-Cheé, Haßler, Jost, Eilders, \& Maurer, 2018) and indicate descriptive norms of how others think about an issue (Go, Jung, \& Wu, 2014). Thereby, such cues can serve as indicators of public opinion (Lee, 2012; Lee \& Jang, 2010).

In sum, these considerations suggest that comments and Likes can affect how readers perceive, elaborate, and evaluate information. In our first study, we will therefore investigate how direct social information that relates to a news post, namely critical user comments, affect the perceived credibility of a news article. In the second study, we replicate this effect and include additional direct and indirect social information that accompanies a critical comment, namely Likes to a comment and reply comments.

\section{Study 1: Effects of User Comments on Credibility Perceptions of a News Article}

Often irrespective of the actual journalistic quality of news articles, many user comments criticize the news articles, particularly a lack of accuracy and impartiality (Prochazka \& Schweiger, 2016). Comments that compliment news articles for fulfilling standards of quality journalism are rare (Prochazka \& Schweiger, 2016). Certainly, critical comments may legitimately depict a lack of professional standards like missing accuracy, 
impartiality, comprehensibility, or topicality. They may validly add further information or opposing views. However, other critical comments may unjustifiably criticize valid and substantiated journalistic content. It is thus relevant to know how critical comments affect readers' perceptions of news articles. Prochazka and colleagues (2018) found that, compared to civil comments, uncivil user comments (i.e., disrespectful comments that include insults, slander, and discrimination against social groups, see also Coe et al., 2014) decreased an article's perceived "formal quality" (p.8), which refers to ethics and comprehensibility. Moreover, the authors found that unreasoned comments, that did not provide arguments for their positions, had a negative effect on the perceived "informational quality" (p.8), which refers to perceived relevance, diversity, and impartiality of the article. However, this effect only occurred for unknown news outlets. While uncivil and unreasoned comments decreased the perceived quality, neither civil nor reasoned comments improved the perceived quality compared to a comment-free version. The authors concluded that the low quality of the comments, marked by their incivility and lack of reasoning, "spilled over" to the perceived quality of the article. However, they did not manipulate the comments' assessment of the article. In contrast, Thorson, Vraga, and Ekdale (2010) found that readers' credibility ratings for a news story increased when the comments were uncivil and ideologically incongruent. The authors explain their findings with social judgment theory, arguing that under the condition of an extreme discrepancy between the tone of the news story and the related comments, the comments might be perceived as considerably less credible than the story. Then, a contrast effect in the observers' judgment behavior can occur, which makes the article appear more credible by comparison. Regarding the valence of comments toward a news article, Kümpel and Springer (2016) found that user comments that made negative statements about the accuracy and impartiality of a news article decreased the perceived accuracy and impartiality of the news article compared to comments with positive 
assessment. Dohle (2018) arrived at similar results: Participants rated the perceived quality of a news article (measured in terms of transparency, impartiality, completeness, correctness) as lower when the article was accompanied by comments that assessed the article's transparency, completeness, impartiality, and correctness in a predominantly negative way compared to when these attributes of the article were assessed in a predominantly positive way.

The criteria of news perception that the studies which we reviewed assessed (e.g., Kümpel \& Springer, 2016; Prochazka et al., 2018; Thorson et al., 2010) in some parts overlap with criteria of news credibility perception (Flanagin \& Metzger, 2000). We therefore test if civil comments proposing views dissonant to a news article and devaluating the journalistic quality decrease the readers' credibility judgment of the article. We postulate:

H1: Critical user comments will reduce the perceived credibility of a news article compared to an article that received supporting comments or no comments.

\section{Method}

Design and participants. To test our hypothesis, we conducted a $2 \times 2$ betweensubjects experiment. We varied the comment valence (supportive vs. critical) and the context in which the article and the comment thread were presented (two different German news media outlets). We also included an additional comment-free control group. Undergraduate students of a large university in Germany participated voluntarily. Two hundred twenty-six participants were randomly assigned to one of the five conditions. Seventy-seven percent of these participants were female and the mean age was 21 years $(S D=2.39)$.

Procedure and stimuli. Participants in the experimental conditions were shown one of four versions of a news article about so-called superfoods with two user comments below. The article, which criticized superfoods as a "sales pitch", was identical across all groups. At the time of the survey, that issue was rather novel in Germany and not yet frequently present 
in the media. Manipulating the valence of the user comments, one half of the participants were exposed to two user comments supporting the article's quality as well as its point of view regarding superfoods (supportive comments). The other participants were shown two user comments criticizing the article's point of view and quality (critical comments). The comments were written in a civil tone. Based on the finding that reasoned user comments have a higher persuasive impact (Winter, 2013), all user comments provided reasons for their claims. For example, the first critical comment referenced further information to criticize that the article was undifferentiated and polemic. The second comment claimed that the article contained false information. The supportive comments complimented the article and provided additional information supporting the article's arguments.

To control for the potential influence of different news outlets on the presumed effect, the article was labelled to either originate from the online news site of Sueddeutsche Zeitung, which is known as a well-respected, high-quality national German newspaper, or the news site of the BILD-Zeitung, which is a German tabloid known for its sensationalist coverage. The stimulus material is available in the Online Appendix 1.

Participants of the control group were exposed to a version of the article without user comments and without indication of a news outlet.

Pretest. The construct validity of the stimulus material regarding direction and persuasiveness of the news article and the valence of the user comments was ensured in two web-based pretests with a total of 50 participants.

Measures. Unless noted otherwise, we measured all variables on five-point scales ranging from 1 = I completely disagree to $5=$ I fully agree .

After exposure to the stimulus, participants rated the perceived credibility of the news article on five items (e.g., "reliable", "believable", $\alpha=.83, M=3.39, S D=0.67$; Appelman \& Sundar, 2016). 
For the treatment check, we asked the participants how they perceived the valence of the user comments toward the article (five-point scale from $1=$ very negative to $5=$ very positive, $M=2.65, S D=1.22$ ) and the extent of criticism toward the article (e.g., "the user comments criticized the credibility of the article", 3 items, $\alpha=.89, M=3.17, S D=1.20$ ).

Additionally, we measured various control variables. More specifically, we measured participants' involvement in the issue of healthy nutrition (e.g., "important", "interesting", 4 items, $\alpha=.84, M=3.87, S D=0.76$; Zaichkowsky, 1985) and participants' general trust in established news media (e.g., "can be trusted", "are accurate", 6 items, $\alpha=.85, M=3.22, S D$ $=0.63$; Tsfati \& Cappella, 2003). Participants' age and gender were recorded at the end of the survey.

\section{Results}

Treatment check. An ANOVA showed that the manipulation of the valence of the user comments was successful: Participants exposed to supportive comments perceived the comments as more positive toward the article $(M=3.45, S D=1.21)$ than participants who read the critical comments $(M=1.95, S D=0.66), F(1,183)=112.67, p<.001, \eta p^{2}=.38$. In addition, readers of the critical comments perceived these comments as more critical towards the article $(M=4.12, S D=.53)$ than readers of supportive comments $(M=2.01, S D=0.89)$, $F(1,183)=359.89, p<.001, \eta p^{2}=.66$.

Hypothesis testing. To test H1, we compared participants' perceptions of the article's credibility depending on the valence of the user comments using a one-way ANCOVA model. The news outlet was included as an additional factor, and general media trust and issue involvement were included as covariates. We observed a main effect of the valence of the user comments on perceived article credibility, $F(1,162)=29.49, p<.001, \eta p^{2}=.15$. The brand of the news outlet was also significantly related to perceived article credibility, $F(1$, 162) $=14.89, p<.001, \eta p^{2}=.08$. The article was perceived more credible when it appeared 
to be published by the reputable Sueddeutsche Zeitung rather than the tabloid Bild-Zeitung. However, there was no significant interaction effect between comment valence and news outlet, $F(1,162)=0.001, p=.98$. The covariates media trust, $F(1,162)=2.51, p=.12$, and involvement, $F(1,162)=1.10, p=.30$, were not significantly related to perceived article credibility. Planned contrasts revealed that participants who were exposed to critical user comments perceived the related article as less credible $(M=3.06, S D=0.68)$ than participants in the supportive comments condition $(M=3.64, S D=0.66), p<.001,95 \% \mathrm{CI}[-$ $0.81,-0.31]$. In addition, critical user comments decreased the perceived article credibility $(M$ $=3.06, S D=0.68)$ compared to a version without comments $(M=3.64, S D=0.42), p=.001$, 95\% CI [-0.90, -0.20]. Thus, H1 is supported. No significant differences of credibility perception between participants of the supportive comments condition and the control group were found, $p=1.00,95 \%$ CI [-0.36, 0.35].

\section{Study 2: The Influence of User-User-Interaction and User-Moderator- Interaction on Perceived News Article Credibility}

The results of the first study suggest that even very few critical comments can reduce readers' credibility evaluations of a news article. The second study aims at contributing a deeper understanding how further interactions with critical user comments by other users and professional community moderators alleviate or even boost the negative effects of these comments on readers' credibility perceptions. Additionally, study 2 intends to replicate the findings of study 1 (additional test of $\mathrm{H} 1$, see above). To lend greater generalizability to the findings, we use novel stimulus material regarding topic, comments, and platform (Facebook instead of an online news site).

Influence of Social Information Accompanying a Critical Comment: Likes and Reply Comments by Users 
It is the very nature of social media that users respond to other users' content and receive feedback themselves. In fact, most social media platforms and comment sections on news websites provide a reply function and evaluation buttons for comments. Ksiazek and colleagues (2016) have conceptualized the use of these functions as user-user-interactions. Content analyses show that users regularly refer to other users in their comments and that they frequently use evaluation buttons (e.g., Coe et al., 2014). Thus, they complement existing user comments with direct and indirect social information (Kalch \& Naab, 2017; Naab, Kalch, \& Meitz, 2018; Peter et al., 2014).

In previous sections, we elaborated how user-generated social information accompanying news articles may affect readers' perceptions of this journalistic content. We propose that the theoretical assumptions regarding the effects of these user-contentinteractions can be transferred to user-user-interactions and the effects of direct and indirect social information accompanying user comments. In other words, we assume that replies and Likes to user comments should lead to similar effects as comments and Likes to journalistic content. Indeed, Go and colleagues (2014) showed that both the social information on a Facebook page in general and the social information to related user comments influenced users' perceptions of source credibility. Other researchers have added that a high number of Likes to a user comment can increase the impact of that comment on the perceptions of recipients because these Likes convert a single case into an exemplar that represents the attitudes or experiences of a larger social group (Peter et al., 2014). However, so far, studies have not investigated the effects of social information on readers' credibility assessments in a news context.

This study investigates the effects of both Likes and reply comments to critical comments. As previously described, a high number of comment Likes should increase the persuasive value of the respective comment. Similarly, regarding reply comments, an 
agreeing reply to a comment should make the respective comment more persuasive. In contrast, similar to the effects of a critical user comment to a journalistic article, a disagreeing reply to a comment is assumed to reduce the persuasive value of the respective comment. In sum, we hypothesize:

H2: An article accompanied by a critical user comment is perceived as less credible when the comment has received Likes compared to a version with a critical comment without Likes.

H3: An article accompanied by a critical user comment is perceived as more credible when the comment has received a disagreeing reply comment by another user compared to when the critical comment has received an agreeing reply by another user or no reply.

\section{Influence of Interactive Moderation by the Media Outlet}

In the previous section, we argued that the negative effect of critical comments on the credibility of a news article could potentially be reduced or neutralized when users respond to these comments with disagreeing reply comments. However, users' participation in comment sections is voluntary and users might not be motivated or feel no need to engage with comments of others. In contrast to that, news outlets themselves have an interest in preserving an attractive discussion space for their readers, safeguarding their image, and recognize legal responsibility (Stroud, Scacco, Muddiman, \& Curry, 2015; Ziegele \& Quiring, 2013; Vujnovic, 2011). Besides various techniques like automated tools of content moderation and flagging mechanisms, media outlets consider how professional community moderators themselves could respond to comments. Such responses to user comments have been investigated under the label of interactive moderation (Marchionni, 2015; Stroud et al., 2015; Wright et al., 2019). Stroud and colleagues (2015), for example, showed that moderators who ask and encourage questions and share additional information can improve the deliberative quality of comments. Interactive moderation of uncivil user comments also makes readers 
perceive the discussion atmosphere as more deliberative, which in turn can increase their willingness to participate (Wise, Hamman, \& Thorson, 2006; Ziegele \& Jost, 2016).

In this study, we are interested in whether professional moderators can engage with critical user comments in a similar way as users potentially can (see H3) to prevent negative effects on readers' credibility perception by critical comments that they perceive as inappropriate for one reason or another. In fact, professional engagement through elaborate replies to critical user comments could increase the salience of quality differences between the user comment and the journalistic content. Such a contrast effect could then increase the perceived credibility of the journalistic content (Thorson et al., 2010). Additionally, the pure signal of social presence of media actors through moderation comments could make users more aware that there are distinct individuals behind the otherwise anonymous media organization. This might in turn lead to more favorable credibility judgments as individuals usually receive higher ratings than institutions (Hassanein \& Head, 2007; Marchionni, 2015; Newhagen \& Nass, 1989). On the other hand, comment spaces provide an important forum for counter voices including reader criticism of media actors and journalistic standards and processes. Readers thus might consider interactive moderation of critical user comments as inappropriate defensive reactions, and this perception could negatively impact the perception of journalistic impartiality and ultimately result in a loss of credibility (Diakopoulos \& Naaman, 2011).

To our knowledge, no study has investigated how interactive moderation contradicting a critical comment influences readers' judgment of the credibility of the products of a media outlet - particularly in comparison with a disagreeing reply comment that is written by an ordinary user. Thus, we ask: 
RQ1: Does it affect the perceived credibility of an article when a critical user comment receives a disagreeing reply by either a professional community moderator, another user, or no reply at all?

\section{Method}

Design and participants. We set up an unbalanced between-subject experimental design that included nine different versions of a discussion thread below a news article about vaccinations on a Facebook page. We varied 1) whether a critical user comment below the news article had received Likes (Likes vs. no Likes), 2) whether the critical user comment had received a reply comment by a professional community moderator, by another user, or whether it did not receive a reply comment at all (moderator vs. user vs. no reply). Finally, in the conditions in which the reply comment was written by another user, we varied 3) whether the user agreed or disagreed with the critical comment. Additionally, we included a control group that did not see a critical user comment or a reply comment below the news article (see table 1 for an overview of the experimental groups).

[Insert Table 1 about here]

We distributed the link to the survey across a wide variety of diverse open Facebook groups (including groups on pets, sports, music, education, computers, and various hobbies). While this would still leave us with a convenience sample, we expected to generate some variance regarding the sociodemographic and psychographic backgrounds of the participants. Four hundred sixty-four participants were randomly assigned to one of the experimental conditions or the control group and answered the online questionnaire ( $72 \%$ female; age: $M=26.53, S D=9.08,46 \%$ had received an university degree).

Procedure and stimulus. First, participants indicated their general trust in news media and their involvement in the issue of vaccinations. They were then exposed to a Facebook post about the importance of vaccinations that was posted on the Facebook page of 
a fictitious news magazine (Welt24.de). This issue was chosen because most citizens have some personal experience with the issue and it is subject to controversial debates. Several user comments were added below the post. The number of comments depended on the experimental condition (see below). The first and the last comment in each condition were not manipulated and included neutral statements. After reading the news post and the comments, participants were directed to the next page of the online questionnaire showing the full news article. After that, participants answered questions on their perception of the news article and a treatment check.

The critical user comment blamed the news article for being biased and questioned its credibility very directly. It accused the media outlet of inaccurate reporting and claimed that the pharmaceutical industry has commercial interests in vaccinations and influences scientific studies advocating vaccinations. Thus, the comment put forward arguments commonly offered by vaccination opponents, which are, however, contradictory to scientific evidence on vaccinations.

Regarding the manipulated factor 1), the critical comment had received either no or 33 Likes by other users.

Regarding the manipulated factor 2), the critical comment had received a reply comment in six experimental conditions. The reply comment was posted either by a professional community moderator of the news outlet or by another user. The author of the reply was made identifiable via the profile name and picture ("Welt24" for the professional community moderator vs. "Andreas Liebig" for the user).

Regarding the manipulated factor 3), we varied the valence of the reply comment posted by the user. The reply either agreed or disagreed with the critical comment. In the agreement condition, the commenter indicated that he could fully understand the criticism of the critical comment. He argued that the article was not thoroughly written and that it 
neglected crucial scientific evidence. In the disagreement condition, the author of the reply comment disagreed with the commenter stating that the article was well-written and used reliable sources. In all experimental conditions with a reply by a professional community moderator of Welt24, the moderator posted disagreement. Surely, moderators might respond to criticism in various ways, including admitting errors, asking questions, or providing further evidence. But since the position of the article on vaccinations was clearly backed by scientific evidence, it seemed unrealistic that a professional moderator would support a critical comment that questions the credibility of the article and the evidence for the advocated position on vaccinations. The stimulus material is available in the Online Appendix 2.

Pretest. Prior to the study, we conducted a qualitative and quantitative pretest $(N=$ 31) of the stimulus material. The Facebook post and the news article were perceived as comprehensible and credible, the news article as authentic. Participants also rated several critical as well as neutral comments with varying Like counts. The comment that was perceived as most critical toward the article and as most relevant was used as stimulus material.

Measures. Unless noted otherwise, all variables were measured on seven-point scales ranging from 1 = I completely disagree to $7=$ I fully agree .

Perceived article credibility was measured with the same items as in study $1(\alpha=.81$; $M=4.47 ; S D=1.03)$.

General trust in the news media $(\alpha=.92, \mathrm{M}=3.92, \mathrm{SD}=1.12)$ and issue involvement were measured with the same items as in study $1(\alpha=.82, M=5.28, S D=1.14)$, but of course referring to vaccination instead of healthy nutrition.

Participants perceived the critical comment as critical towards the news article (7 items, $\alpha=.79, M=5.84, S D=0.91)$. For the treatment check, participants rated whether they perceived that the critical comment was appreciated by many users ( 3 items, $\alpha=.95, M=$ 
$3.84, S D=2.05)$. They also indicated whether they perceived the reply comment was written by a user ( 2 items, $\alpha=.89, M=4.42, S D=2.21$ ) and whether it disagreed with the comment (5 items, $\alpha=.92, M=4.75, S D=1.95)$.

\section{Results}

Treatment Check. ANOVAs showed that the manipulations of Like count, author of the reply comment, and valence of the reply comment were successful: The comment with 33 Likes was perceived as more appreciated by other users $(M=5.18, S D=1.40)$ than the comment without Likes $(M=2.50, S D=1.68), F(1,390)=292.87, p<.001, \eta p^{2}=.43$. The reply comment authored by "Andreas Liebig" was perceived as being written by another user $(M=5.70, S D=1.33)$, while the reply comment authored by "Welt24.de" was perceived as being written by a moderator $(M=1.96, \mathrm{SD}=1.32), F(1,290)=524.97, p<.001, \eta p^{2}=.64$. The disagreeing reply comment was perceived as disagreeing much more intensely with the critical comment $(M=5.86, S D=1.03)$ than the reply supporting the critical comment $(M=$ $2.53, S D=1.33), F(1,290)=556.25, p<.001, \eta p^{2}=.66$.

Hypotheses testing. $\mathrm{H} 1$ assumed (as also tested in study 1) that a critical user comment reduces the perceived credibility of a news article compared to an article that received no critical comment. $\mathrm{H} 2$ assumed that an article accompanied by a critical user comment is perceived as less credible when the comment has received Likes compared to a version with a critical comment without Likes. We conducted a one-way ANCOVA to analyze differences of the perceived credibility of the news article in the stimulus conditions 1 without critical comment (control group), condition 2 with a critical comment without Likes, and condition 3 with a critical comment with 33 Likes (see Table 1 for an overview over the conditions and the descriptives of perceived article credibility by conditions). We controlled for general media trust and issue involvement. We found a significant difference in mean perceived credibility of the news article, $F(2,148)=8.32, p<.001, \eta p 2=.10$. The 
article was perceived most credible when it had not received a critical comment (condition 1, control group, $M=4.69, S D=0.85$ ), followed by the article with a critical comment without Likes (condition 2, $M=4.62, S D=0.92$ ). When the critical comment had received 33 Likes, the article was perceived as least credible (condition 3, $M=4.06, S D=0.97$ ). Planned contrasts revealed that a critical comment without Likes did not significantly decrease the perceived credibility of the article compared to the control group without a critical comment, $p=.952,95 \%$ CI $[-0.34,0.32]$. However, when the critical comment had received Likes, the perceived credibility of the article was significantly lower than in the control group, $p<.001$, 95\% CI [-0.94, -0.27]. H1 is partly supported. Planned contrasts also revealed that the perceived credibility of the article was significantly higher when the critical comment had not received Likes than when it had, $p=.001,95 \%$ CI $[0.26,0.94] . \mathrm{H} 2$ is supported. The covariate media trust was not significantly related to perceived credibility, $F(1,148)=3.66, p$ $=.058, \eta p^{2}=.02$. In contrast, involvement was significantly and positively associated with perceived credibility, $F(1,148)=17.59, p<.001, \eta p^{2}=.11$.

$\mathrm{H} 3$ assumed that an agreeing reply comment posted by another user decreases the perceived credibility, and RQ1 asked for the effect of disagreeing reply comments written by another user or a moderator. To test the hypothesis and answer the research question, we conducted a one-way ANCOVA comparing the effects of a critical user comment without reply comment (conditions 2 and 3) with a version with a disagreeing user reply (conditions 4 and 5), a version with a disagreeing moderator reply (conditions 6 and 7), and a version with an agreeing user reply (conditions 8 and 9). We computed an independent factor with the combined information on "valence and author of the reply". We added the Like count of the critical comment (no Likes vs. 33 Likes) as a second independent factor and, again, controlled for general media trust and involvement in the issue of vaccination. We found a significant effect of the variable "valence and author of the reply comment" on the perceived 
credibility of the news article, $F(3,403)=2.72, p=.041, \eta p^{2}=.02$. Testing H3, planned contrasts revealed that the news article was perceived as significantly more credible when the critical comment had received a disagreeing user reply (conditions 4 and 5, $M=4.67, S D=$ 1.10; average across the experimental groups with and without Likes) than when it had not received a reply (conditions 2 and $3, M=4.34, S D=0.98$ ), $p=.027,95 \%$ CI [-0.58, -0.03]. A disagreeing user reply to the critical comment also resulted in a significantly higher perceived article credibility than a critical comment with an agreeing user reply (conditions 8 and 9, $M$ $=4.34, S D=0.99), p=.007,95 \% \mathrm{CI}[-0.64,-0.10]$. An agreeing user reply, however, did not significantly decrease perceived credibility compared to no reply, $p=.631,95 \%$ CI [-0.33, 0.20]. H3 is supported.

Planned contrasts further revealed that the news article was not perceived significantly different when it had received a disagreeing reply by a moderator (conditions 6 and $7, M=4.42, S D=1.09$; average across the experimental groups with and without Likes) compared to when it had not received a reply at all (conditions 2 and 3, $M=4.34, S D=0.98$ ), $p=.719,95 \% \mathrm{CI}[-0.22,0.32]$, and compared to when it had received a disagreeing reply by a user (conditions 4 and 5, $M=4.67, S D=1.10), p=.062,95 \%$ CI [-0.53, 0.01].

There was no significant interaction effect between the two independent variables "valence and author of the reply" and Like count, $F(3,403)=2.20, p=.088, \eta p^{2}=.02$. The covariates media trust, $F(1,403)=22.88, p<.001, \eta p^{2}=.05$, and involvement, $F(1,403)=$ $27.60, p<.001, \eta p^{2}=.06$, were significantly and positively related to perceived article credibility.

\section{Discussion}

This paper investigated how critical user comments affect readers' credibility perceptions of an online news article and how reactions to such comments in the form of Likes and replies change this effect. The first experiment revealed that critical user comments 
on an online news site decreased the perceived credibility of the related news article. The second experiment replicated this finding in a different context and corroborates the conclusions of previous studies that readers use critical user comments as cues to evaluate the quality of news articles (Dohle, 2018; Kümpel \& Springer, 2016). Study 1 showed that this effect occurred for two different media outlets, namely Sueddeutsche Zeitung and BILDZeitung. Although this was not explicitly tested, it indicates that the results might be applicable to high-quality as well as tabloid news outlets.

Certainly, critical comments can serve as a relevant corrective against unsubstantiated or one-sided journalistic content. Scrutinizing an article's credibility will then be an important and desirable function of user comments. It was an aim of the study to examine whether this function can be met and critical comments indeed have an effect. Moreover, many comments express unsubstantiated and across-the-board criticism behind a seemingly civil tone. It is therefore also important to know whether the negative effects of such critical comments can be countered. Consequently, we aimed to shed light on the circumstances that reduce or strengthen the effects of critical comments on readers' credibility attributions. Indeed, study 2 suggests that a critical comment does not always impede readers' credibility attribution compared to a comment thread that does not include a critical comment. It does so, however, when other users indicate their approval of the criticism by pushing the Like button, thereby possibly serving other users as anchoring heuristics (Porten-Cheé, Haßler, Jost, Eilders, \& Maurer, 2018) and indicators of public opinion (Lee, 2012; Lee \& Jang, 2010).

In contrast, additional replies to a critical comment supporting its criticism did not further damage the perceived credibility of the news article. Instead, when another user counter-argued against the criticism in a reply comment, this measure helped to restore the article's perceived credibility. Thus, while aggregated, indirect social information in Likes 
can boost the negative effects of media criticism, exemplar discursive, direct social information in replies can counter it. These findings contribute to a deeper understanding of exemplification effects of user-generated social information. In line with Peter and colleagues (2014), the findings confirm that exemplars in the form of user comments can influence people's perception. Additionally, a disagreeing reply comment by another user countered this effect. Moreover, the second study adds empirical evidence on the impact of indirect social information. The results suggest that Likes may be able to turn a single critical comment into an exemplar representing a larger group of readers.

However, when the critical comment in study 2 received a reply, the Like count also did not change its influence on credibility perceptions anymore. This is in line with research on the influence of exemplars compared to base-rate information. Illustrative individual cases (comparable to individual users' replies) exert stronger effects on opinion formation and perception of public opinion than statistical information (comparable to Like counts; Brosius \& Barthelt, 1994; Lee \& Jang, 2010). Probably, the Like count of 33 Likes in study 2 was too small and it needs to represent a much larger group of people to overwhelm the effect of a disagreeing reply comment. Alternatively, the intended meaning of a Like is hard to interpret (Crawford \& Gillespie, 2016). This might also cause that the more detailed and vivid information of reply comments was more effective. Future exemplification research should further investigate the differences between statistical, indirect social information and discursive, direct social information.

Since user comments are more likely to dismiss news articles than to support them (Prochazka \& Schweiger, 2016) and since many comments include unsubstantiated criticism, editors and community managers might wish to counter particular critical comments. However, the findings of study 2 indicate that it does not increase credibility ratings when a moderator posts a disagreeing reply. Theoretically, this suggests that moderators, who are 
part of the criticized news outlet, might be trusted less than "ordinary" users when trying to counter critical comments. Their interventions could be perceived as illegitimate attempts to direct the conversations of the users (which readers do not approve, see Stroud, van Duyn, \& Peacock, 2016), and, ultimately, as restrictions of free speech. Still, our findings do not suggest that interventions of professional moderators further decrease the perceived credibility of news articles. Beyond these findings on the limited impact of moderators' interventions in comment sections on credibility judgements, journalists and editors are surely well-advised to take critical comments seriously and self-examine the quality of their work.

Stroud and colleagues (2015) report that a recognizable journalist engaging in a comment section was more effective in changing the behavior of comment writers, because individuals are more trusted than institutional actors. In our stimulus material, a media organization instead of an individual reporter replied to the critical comment. Considering the findings from Stroud and colleagues, an individual reporter replying to a critical comment might have an impact on regaining credibility.

With regard to practical considerations, our results suggest that counter-speech to criticism in user comments that one perceives as inappropriate for one reason or another matters to restore readers' credibility perceptions. Disagreeing responses by users can outbalance a Like count of a critical comment. Factual interactive moderation by professionals has also been shown to increase users' perception of a deliberative discussion atmosphere and their willingness to participate in the comment sections (Stroud et al., 2015; Ziegele \& Jost, 2016). Thus, the interventions by moderators might potentially motivate silent readers to engage against overly critical comments themselves. The findings of the present study suggest that this user engagement can in turn influence the credibility of a news outlet's journalistic content. 


\section{Limitations}

Our findings should be interpreted only in light of several methodological limitations. First, the experimental designs in laboratory settings pursued high internal validity. At the same time, this procedure might have forced respondents to read and evaluate news stories they might not be interested in under natural circumstances, thereby reducing the external validity of our findings. The laboratory setting also did not account for the notion that in many comment sections, the Like count of a comment influences the comment's position within the thread. That is, most-liked comments appear more prominently in the thread and thus have a higher likelihood of receiving attention. Taking this into account might influence the effects of Likes to a comment.

Second, both studies are limited to short-term effects of critical comments. Future long-term effects studies might be especially fruitful to understand the underlying processes of elaboration of exemplar and summary statistical social information accompanying news articles. For example, heuristic processing of Likes might probably have a less persistent effect than more elaborate processing of well-reasoned replies. Future studies should also address the effects of repeated exposure to critical comments on perceived news article credibility and possible spiral effects of decreasing appreciation of the whole news outlet.

Third, in the first study, the comparisons with the control group cannot be clearly interpreted because the control group lacked both comments and information about the publishing news media brand. To investigate the effects of a comment-free version compared to supportive and critical comments while also separating the effects of the news outlet, a full 3x2-experimental design would have been necessary.

Finally, both studies drew on convenience samples with an overrepresentation of young and well-educated participants compared to the general population. Since social media news users are indeed younger and better educated than the general population (Perrin, 2015), 
this should not be too much of a limitation to external validity. However, well-educated users tend to be more critical of online news outlets, while younger users seem to put higher trust in these outlets (Johnson \& Kaye, 1998). Thus, future studies need to extend the findings to more robust samples.

\section{Conclusion}

In times when trust in established news media is repeatedly questioned, a closer understanding of the determinants of news credibility is inevitable. Our findings provide important implications for research on credibility perceptions in online environments and on the effects of critical comments, civil user-user-interactions, and interactive journalistic moderation. The findings underline the potential of critical user comments to serve as a corrective to deficient journalistic work, but, at the same time, the findings also illustrate that unjustified criticism in comment sections can affect the credibility of proper journalistic products in negative ways. In such cases, our results shed light on the differentiated effects of counter-speech on regaining credibility. Future research should continue to examine these dynamics in online discussions. 


\section{References}

Appelman, A., \& Sundar, S. S. (2016). Measuring message credibility. Journalism \& Mass Communication Quarterly, 93(1), 59-79. https://doi.org/10.1177/1077699015606057

Bergström, A., \& Wadbring, I. (2015). Beneficial yet crappy: Journalists and audiences on obstacles and opportunities in reader comments. European Journal of Communication, 30(2), 137-151. https://doi.org/10.1177/0267323114559378

Brosius, H.-B., \& Barthelt, A. (1994). The utility of exemplars in persuasive communications. Communication Research, 21(1), 48-78. https://doi.org/10.1177/009365094021001004

Craft, S., Vos, T. P., \& David Wolfgang, J. (2016). Reader comments as press criticism: Implications for the journalistic field. Journalism, 17(6), 677-693. https://doi.org/10.1177/1464884915579332

Crawford, K. \& Gillespie, T. (2016). What is a flag for? Social media reporting tools and the vocabulary of complaint. New Media \& Society, 18(3), 410-428. https://doi.org/10.1177/1461444814543163

Coe, K., Kenski, K., \& Rains, S. A. (2014). Online and uncivil? Patterns and determinants of incivility in newspaper website comments. Journal of Communication, 64, 658-679. https://doi.org/10.1111/jcom.12104

Diakopoulos, N. A., \& Naaman, M. (2011). Towards quality discourse in online news comments. In CSCW'11 Proceedings of the ACM 2011 conference on computer supported cooperative work (pp. 133-142). New York, NY: ACM.

Dohle, M. (2018). Recipients' assessment of journalistic quality. Digital Journalism, 6(5), 563-582. https://doi.org/10.1080/21670811.2017.1388748

Duffy, A., Ling, R., \& Tandoc, E. C. (2018). The people have spoken (the bastards?). Journalism Practice, 12(9), 1130-1147. https://doi.org/10.1080/17512786.2017.1372696 
Fichter, C., \& Jonas, K. (2008). Image effects of newspapers: How brand images change consumers' product ratings. Journal of Psychology, 216(4), 226-234.

Flanagin, A. J., \& Metzger, M. J. (2000). Perceptions of internet information credibility. Journalism \& Mass Communication Quarterly, 77(3), 515-540. https://doi.org/10.1177/107769900007700304

Fletcher, R., \& Park, S. (2017). The impact of trust in the news media on online news consumption and participation. Digital Journalism, 5(10), 1281-1299.

Go, E., Jung, E. H., \& Wu, M. (2014). The effects of source cues on online news perception. Computers in Human Behavior, 38, 358-367. https://doi.org/10.1016/j.chb.2014.05.044

Haim, M., Kümpel, A. S., \& Brosius, H.-B. (2018). Popularity cues in online media: A review of conceptualizations, operationalizations, and general effects. Studies in Communication and Media, 7(2), 58-79. https://doi.org/10.5771/2192-4007-2018-2-58

Hassanein, K., \& Head, M. (2007). Manipulating perceived social presence through the web interface and its impact on attitude towards online shopping. International Journal of Human-Computer Studies, 65(8), 689-708. https://doi.org/10.1016/j.ijhcs.2006.11.018

Heinbach, D., Ziegele, M., \& Quiring, O. (2018). Sleeper effect from below: Long-term effects of source credibility and user comments on the persuasiveness of news articles. New Media \& Society, 20(12), 4765-4786. doi: 10.1177/1461444818784472

Jin, S. V., Phua, J., \& Lee, K. (2015). Telling stories about breastfeeding through Facebook: The impact of user-generated content (UGC) on pro-breastfeeding attitudes. Computers in Human Behavior, 46, 6-17. https://doi.org/10.1016/j.chb.2014.12.046

Johnson, T. J., \& Kaye, B. K. (1998). Cruising is believing? Comparing internet and traditional sources on media credibility measures. Journalism \& Mass Communication Quarterly, 75(2), 325-340. https://doi.org/10.1177/107769909807500208 
Kalch, A., \& Naab, T. K. (2017). Replying, disliking, flagging: How users engage with uncivil and impolite comments on news sites. SCM Studies in Communication/Media, 6(4), 395-419. https://doi.org/10.5771/2192-4007-2017-4-395

Kohring, M., \& Matthes, J. (2007). Trust in News Media. Communication Research, 34(2), 231-252. https://doi.org/10.1177/0093650206298071

Ksiazek, T. B., Peer, L., \& Lessard, K. (2016). User engagement with online news: Conceptualizing interactivity and exploring the relationship between online news videos and user comments. New Media \& Society, 18(3), 502-520. https://doi.org/10.1177/1461444814545073

Kümpel, A. S., \& Springer, N. (2016). Commenting quality: Effects of user comments on perceptions of journalistic quality. Studies in Communication and Media, 5(3), 353-366. https://doi.org/10.5771/2192-4007-2016-3-353

Lee, E.-J. (2012). That's not the way it is: How user-generated comments on the news affect perceived media bias. Journal of Computer-Mediated Communication, 18, 32-45. https://doi.org/10.1111/j.1083-6101.2012.01597.x

Lee, E.-J., \& Jang, Y. J. (2010). What do others' reactions to news on internet portal sites tell us? Effects of presentation format and readers' need for cognition on reality perception. Communication Research, 37(6), 825-846. https://doi.org/10.1177/0093650210376189

Loke, J. (2012). Old turf, new neighbors: Journalists' perspectives on their new shared space. Journalism Practice, 6(2): 233-49.

MacGregor, P. (2014). Siren songs or path to salvation? Interpreting the visions of Web technology at a UK regional newspaper in crisis, 2006-2011. Convergence: The International Journal of Research into New Media Technologies, 20(2), 157-175. https://doi.org/10.1177/1354856512472605 
Marchionni, D. (2015). Journalism-as-a-conversation: An experimental test of sociopsychological/technological dimensions in journalist-citizen collaborations. Journalism, 16(2), 218-237. https://doi.org/10.1177/1464884913509783

McCluskey, M. \& Hmielowksi, J. (2011). Opinion expression during social conflict: Comparing online reader comments and letters to the editor. Journalism, 13 (3), 303-319. https://doi.org/ 10.1177/1464884911421696

Messing, S., \& Westwood, S. J. (2014). Selective exposure in the age of social media. Communication Research, 41(8), 1042-1063. https://doi.org/10.1177/0093650212466406

Metzger, M. J., Flanagin, A. J., \& Medders, R. B. (2010). Social and heuristic approaches to credibility evaluation online. Journal of Communication, 60(3), 413-439. https://doi.org/10.1111/j.1460-2466.2010.01488.x

Naab, T. K., Kalch, A., \& Meitz, T. G. (2018). Flagging uncivil user comments: Effects of intervention information, type of victim, and response comments on bystander behavior. New Media \& Society, 20(2), 777-795. https://doi.org/10.1177/1461444816670923

Newhagen, J., \& Nass, C. (1989). Differential criteria for evaluating credibility of newspapers and TV news. Journalism Quarterly, 66(2), 277-284. https://doi.org/10.1177/107769908906600202

Perrin, A. (2015). Social media usage: 2005-2015. Retrieved from https://www.pewinternet.org/2015/10/08/social-networking-usage-2005-2015/

Peter, C., Rossmann, C., \& Keyling, T. (2014). Exemplification 2.0. Journal of Media Psychology, 26(1), 19-28. https://doi.org/10.1027/1864-1105/a000103

Petty, R. E., \& Cacioppo, J. T. (1986). Communication and persuasion: Central and peripheral routes to attitude change. Springer Series in Social Psychology. Berlin, Germany: Springer. 
Porten-Cheé, P., Haßler, J., Jost, P., Eilders, C., \& Maurer, M. (2018). Popularity cues in online media: Theoretical and methodological perspectives. Studies in Communication and Media, 7(2), 208-230. https://doi.org/10.5771/2192-4007-2018-2-208

Prochazka, F., \& Schweiger, W. (2016). Medienkritik online. Was kommentierende Nutzer am Journalismus kritisieren [Media criticism online. What commenting users criticize about journalism]. Studies in Communication and Media, 5(4), 454-469. https://doi.org/10.5771/2192-4007-2016-4-454

Prochazka, F., Weber, P., \& Schweiger, W. (2018). Effects of civility and reasoning in user comments on perceived journalistic quality. Journalism Studies, 19, 62-78. https://doi.org/10.1080/1461670X.2016.1161497

Reich, Z. (2011). User comments: The transformation of participatory space. In J. B. Singer, A. Hermida, D. Domingo, A. Heinonen, S. Paulussen, T. Quandt, ... M. Vujnovic (Eds.), Participatory journalism: Guarding open gates at online newspapers (pp. 96-117).

Chichester, UK: Wiley-Blackwell.

Robinson, S. (2010). Traditionalists vs. convergers: Textual privilege, boundary work, and the journalist-audience relationship in the commenting policies of online news sites. Convergence: The International Journal of Research into New Media Technologies, 16(1), 125-143. https://doi.org/10.1177/1354856509347719

Ruiz, C., Domingo, D., Micó, J. L., Díaz-Noci, J., Meso, C., \& Masip, P. (2011). Public Sphere 2.0? The Democratic Qualities of Citizen Debates in Online Newspapers. The International Journal of Press/Politics, 16, 463-487.

Springer, N., Engelmann, I., \& Pfaffinger, C. (2015). User comments: motives and inhibitors to write and read. Information, Communication \& Society, 18(7), 798-815. 
Stroud, N. J., Scacco, J. M., Muddiman, A., \& Curry, A. L. (2015). Changing deliberative norms on news organizations' Facebook sites. Journal of Computer-Mediated Communication, 20(2), 188-203. https://doi.org/10.1111/jcc4.12104

Thorson, Kjerstin, Vraga, E., \& Ekdale, B. (2010). Credibility in context: How uncivil online commentary affects news credibility. Mass Communication and Society, 13(3), 289-313. https://doi.org/10.1080/15205430903225571

Tsfati, Y., \& Cappella, J. N. (2003). Do people watch what they do not trust? Exploring the association between news media skepticism and exposure. Communication Research, 30(5), 504-529. https://doi.org/10.1177/0093650203253371

Tsfati, Y., Meyers, O., \& Peri, Y. (2006). What is good journalism? Comparing Israeli public and journalists' perspectives. Journalism: Theory, Practice \& Criticism, 7(2), 152-173. https://doi.org/10.1177/1464884906062603

Urban, J., \& Schweiger, W. (2014). News quality from the recipients' perspective. Journalism Studies, 15(6), 821-840. https://doi.org/10.1080/1461670x.2013.856670

Viscovi, D., \& Gustafsson, M. (2013). Dirty work: Why journalists shun reader comments. In T. Olsson (Ed.), Producing the Internet: Critical Perspectives of Social Media (pp. 85102). Göteborg: Nordicom.

Vujnovic, M. (2011). Participatory journalism in the marketplace. Economic motivations behind the practices. In J. B. Singer, A. Hermida, D. Domingo, A. Heinonen, S. Paulussen, T. Quandt, ... M. Vujnovic (Eds.), Participatory journalism: Guarding open gates at online newspapers (pp. 139-154). Malden, MA: Wiley-Blackwell.

Weinreich, H., Obendorf, H., Herder, E., \& Mayer, M. (2008). Not quite the average. ACM Transactions on the Web, 2(1), 1-31. https://doi.org/10.1145/1326561.1326566 
Wendelin, M., Engelmann, I., \& Neubarth, J. (2017). User rankings and journalistic news selection. Journalism Studies, 18(2), 135-53.

https://doi.org/10.1080/1461670X.2015.1040892

Winter, S. (2013). Lost in Information? Sozialpsychologische Aspekte der Selektion und Rezeption von journalistischen Online-Angeboten [Lost in information? Social psychological aspects of selection and reception of journalistic online content]. Stuttgart, Germany: Kohlhammer.

Wise, K., Hamman, B., \& Thorson, K. (2006). Moderation, response rate, and message interactivity: Features of online communities and their effects on intent to participate. Journal of Computer-Mediated Communication, 12, 24-41. https://doi.org/10.1111/j.1083-6101.2006.00313.x

Wright, S., Jackson, D., \& Graham, T. (2019). When journalists go "below the line": Comment spaces at The Guardian (2006-2017). Journalism Studies, 29(4), 1-20. https://doi.org/10.1080/1461670X.2019.1632733

Zaichkowsky, J. L. (1985). Measuring the involvement construct. Journal of Consumer Research, 12(3), 341. https://doi.org/10.1086/208520

Ziegele, M., \& Jost, P. B. (2016). Not funny? The effects of factual versus sarcastic journalistic responses to uncivil user comments. Communication Research. Advance online publication. https://doi.org/10.1177/0093650216671854

Ziegele, M., \& Quiring, O. (2013). Conceptualizing Online Discussion Value: A Multidimensional Framework for Analyzing User Comments on Mass-Media Websites. Annals of the International Communication Association, 37(1), 125-153. https://doi.org/10.1080/23808985.2013.11679148 
Zillmann, D. (2002). Exemplification theory of media influence. In J. Bryant \& D. Zillmann (Eds.), Media effects: advances in theory and research (pp. 19-41). Mahwah, NJ: Lawrence Erlbaum. 


\section{Tables}

Table 1

Overview Over the Conditions in Study 2 and Means and Standard Deviations of the Perceived Article Credibility by Condition

\begin{tabular}{|c|c|c|c|c|}
\hline Condition & $\begin{array}{l}\text { critical } \\
\text { comment } \\
\text { below news } \\
\text { post }\end{array}$ & $\begin{array}{l}\text { critical } \\
\text { comment } \\
\text { received } \\
\text { Likes }\end{array}$ & $\begin{array}{l}\text { critical comment } \\
\text { received reply } \\
\text { comment } \\
\text { (valence/author) }\end{array}$ & $\begin{array}{l}\text { Perceived article } \\
\text { credibility } M(S D)\end{array}$ \\
\hline 1: Control group & no & n.a. & n.a. & $M=4.69(S D=0.85)$ \\
\hline $\begin{array}{l}\text { 2: Experimental } \\
\text { group }\end{array}$ & yes & no & no & $M=4.62(S D=0.92)$ \\
\hline $\begin{array}{l}\text { 3: Experimental } \\
\text { group }\end{array}$ & yes & yes & no & $M=4.06(S D=0.97)$ \\
\hline $\begin{array}{l}\text { 4: Experimental } \\
\text { group }\end{array}$ & yes & no & $\begin{array}{l}\text { yes: disagreeing } \\
\text { reply by user }\end{array}$ & $M=4.66(S D=1.04)$ \\
\hline $\begin{array}{l}\text { 5: Experimental } \\
\text { group }\end{array}$ & yes & yes & $\begin{array}{l}\text { yes: disagreeing } \\
\text { reply by user }\end{array}$ & $M=4.67(S D=1.18)$ \\
\hline $\begin{array}{l}\text { 6: Experimental } \\
\text { group }\end{array}$ & yes & no & $\begin{array}{l}\text { yes: disagreeing } \\
\text { reply by moderator }\end{array}$ & $M=4.38(S D=1.09)$ \\
\hline $\begin{array}{l}\text { 7: Experimental } \\
\text { group }\end{array}$ & yes & yes & $\begin{array}{l}\text { yes: disagreeing } \\
\text { reply by moderator }\end{array}$ & $M=4.46(S D=1.09)$ \\
\hline
\end{tabular}


8: Experimental yes

group

9: Experimental yes

group no

yes: agreeing reply

$M=4.35(S D=1.06)$

by user

yes

yes: agreeing reply

$M=4.32(S D=0.91)$

by user 


\section{Online Appendix}

Online Appendix 1

Stimulus in Study 1: News Article and User Comments (Original German Version Translated to English)

29th December 2015, 14:28 Diet

Sales Pitch Superfoods

Superfoods promise to increase healthy nutrition. But what's the real deal with chia seeds, goji and açaí berries?

By Franz Kotteder

A healthy diet is the alpha and omega of life. Some foods are even attested supernatural qualities. At least in the comic. What would be the brave sailor Popeye without his spinach? A can of it and the sailor becomes a superhero, knocking every opponent out of his boots. Popeye's spinach literally is the prototype of superfood: A food that grants special powers. Of course, what is currently advertised as "superfoods" - a rather unusual plural in English - is not supposed to help in a brawl, but rather to make its consumers incredibly healthy and help them stay healthy.

Even Jamie Oliver is not quite sure about the empirical evidence regarding the many superfood superlatives

Now even the British television chef Jamie Oliver has published a book about superfood.

This is always a sure sign that a trend is on the verge of reaching the mainstream of society. According to Oliver, "Everyday Superfood" (Dorling Kindersley Publishers, 312 pages, 24,95 euros) is about spreading knowledge about healthy dieting. This does not sound very spectacular and is not very spectacular either. In fact, the media professional is surprisingly 
holding back on promises of the effects of superfood. His "Super-food protein loaf" recipe just says: "It helps the muscles to heal and grow."

However, experts brand the hype about superfoods as nonsense. Hans Hauner, Professor for Nutritional Medicine at the Technical University of Munich, says: "Superfood is nothing but a PR-term used to make a deal." It always works in the same way: You take a seed or a berry with a special, high nutritional value from a foreign country and claim it is particularly healthy. "The small portion these foods include is so trivial, that it does not make a big difference". According to Hauner, this is the reason why there are virtually no scientific studies that confirm positive effects or demonstrate advantages of superfood over native varieties.

The simple, old spinach is just as healthy as superfoods Nevertheless, many in the food industry are counting on the growing trend. Particularly vegans lust for a new healthy cookbook every half year. For them, superfoods make the most sense because they can compensate for the nutrients vegans otherwise miss for lack of meat and milk. Everyone else does not need to be afraid by going without quinoa, lucuma and sweet lupins. Most people can, just as Popeye did, stay with the ordinary spinach. It does not have to be straight from the can though. 


\section{Supportive comments}

Comment 1 Good article! It seems that somebody in the editorial office actually made the effort to analyze the whole thing more realistically. By the way, there are now studies that doubt the benefit of "superfoods":

https://www.klinikum.uni-

heidelberg.de/19.138838.0.html

\section{Critical comments}

What a poor article! "Experts brand the hype about superfoods as nonsense.” Perhaps if you understand the editorial staff as “experts". Real experts would never write such an undifferentiated and polemic article.

Here is one of the many examples of what can also be understood under the term "superfoods": https://www.klinikum.uniheidelberg.de/19-BrokkoliCo.138838.0.html

So sad to read wrong information about this topic in the article once again. "Superfoods" are not only chia seeds, goji berries etc., but everyday food like carrots, avocado, pitch. Until now, I've always liked sesame, and sunflower seeds. his cookbooks. It's not the first time I I do not know about you, but I have read that chia seeds can be harmful. not yet seen overpriced carrots in the And yet, the producers continue supermarket labelled "superfoods". selling products with the label 
"superfood" at horrendous prices and

people fall for it. By the way, carrots

contain more vitamin A than other

edibles (because of the beta-

carotene) and sesame is good for

digestion. Should you therefore

demand three times the usual price

for it?
Please do your research properly

before ranting about this "hype"! By

the way, various studies show the positive effects of superfoods, even of chia seeds \& co. 
Online Appendix 2

Stimulus in Study 2: Facebook Post and User Comments

(English Translation Below the Picture)

Welt24,de

Gestern um 14.55 Uhr - e

Sind Sie skeptisch, was impfungen angeht?

Lesen Sie hier sieben Fakten, die am Ende füs Impfen sprechen.

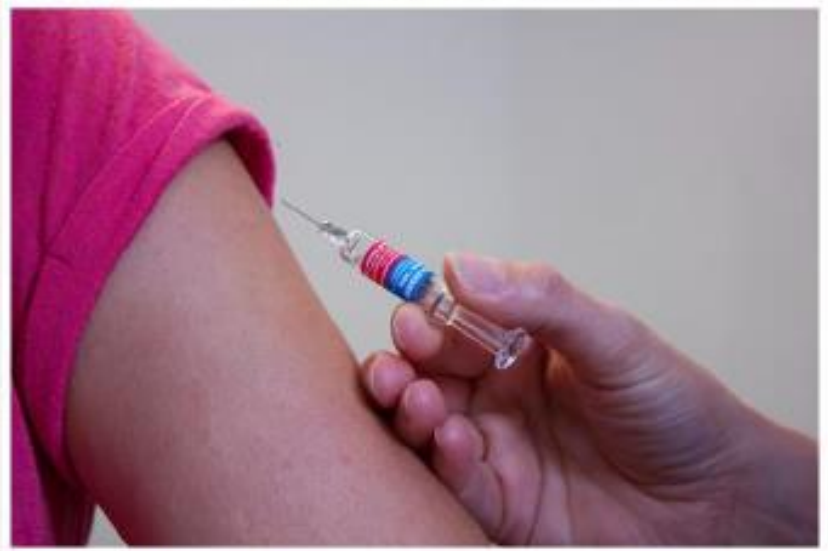

\section{Streitfall Impfungen}

Sie sind eine der größten Errungenschaften der Medizin, doch viele Menschen halten sie fur unnotig oder gar schädlich. Wie viel Skepsis ist berechtigt?

WELT24 DE I VON WELTZ4 ONUNE GMBH, BERUN, Germany

If Gefallt mir win Kommentieren $\rightarrow$ Teilen

Heidrun Ziegler SChau mal @Melanie Schmidt

Gefallt mir - Antworten - 31 Mir

Lena-Marie Winkler Bei solcher Art von Berichterstattung wundert es mich nicht dass euch keiner mehr glauben schenkt... Der Artikel kingt wie aus der Feder enes Pharmalobbyisten und beinhaltet keine krtische Auseinandersetzung. Sorgfatiger Journalsmus sieht anderes aus!!! Unstrittig ist, dass Impfungen einen millardenschweren Markt für die Hersteller ausmachen. Deren Enfuss auf Wosenschaft, Poltk und Medien ist offensichtich. Enige der "Wissenschaftler", die die Pro-Impfen-Studien herausgeben sind sebst in der Impistoff-Industrie beschaftigt. Denen kann man nicht glauben.

Gefall mir Antworten - 28 Min

NA Andreas Liebig Ich kann die Kritk sehr gut nachvolziehen und finde den Artkel auch nicht sorgfalig geschrieben, da er kritische, wissenschaftiche Ergebnisse auslasst... Anders als im Artikel dargestelt, ist eine Skepsis gegenuber dem Impfen sehr wohl begrundet. Impfungen solten hinterfragt werden, um sich vor Nebenwirkungen und Schaden zu schutzen.

Gefallt mir -Antworten 17 Min

Kerstin Maler immer wieder dieses Thema $*$.

Gefallt mir Antworten $12 \mathrm{Min}$

\section{Welt24.de}

Yesterday at $2.55 \mathrm{pm}$

Are you skeptical about vaccinations? 
Read seven facts here that speak for vaccinations in the end.

Issue vaccinations

They are one of the largest achievements of medicine. Still many people perceive them as unnecessary or even harmful. How much skepticism is justified?

\section{Neutral comment 1:}

Heidrun Ziegler: Look @ Melanie Schmidt

\section{Critical comment (in conditions 2 to 9):}

Lena-Marie Winkler: With such sort of reporting I don't wonder that no one believes in you... The article sounds like penned by a pharma lobbyist and contains no critical contention. Careful journalism looks different!!! It is undisputed that vaccinations constitute a multi-billion market for producers. Their influence on science, politics and media is obvious. Some "scientists" who publish pro-vaccination studies are themselves employed in the vaccine industry. You cannot trust them.

\section{Reply comments to the critical comment}

\section{Disagreeing reply comment posted by user "Andreas Liebig" (in conditions 4 and 5)}

Andreas Liebig: I cannot reconstruct your criticism, since the article is carefully written and provides reliable scientific evidence. As presented in the article, a skepticism against vaccinations is barely justified. Vaccinations should be taken seriously to prevent infections and diseases.

\section{Disagreeing reply comment posted by moderator „Welt 24.de” (in conditions 6 and 7)}

Welt 24.de: We cannot reconstruct your criticism, since the article is carefully written and provides reliable scientific evidence. As presented in the article, skepticism against vaccinations is barely justified. Vaccinations should be taken seriously to prevent infections and diseases. 
Agreeing reply comment posted by user "Andreas Liebig" (in conditions 8 and 9)

Andreas Liebig: I can fully understand your criticism and I, too, find the article carelessly written, since it ignores critical, scientific results. Different from the presentation in the article, skepticism against vaccinations is very well justified. Vaccinations should be scrutinized to prevent side effects and damage. 